\title{
Determination of priority nature conservation areas and human disturbances in the Yangtze River Basin, China
}

\author{
Zhang Lu ${ }^{a}$, Xu Wei-hua ${ }^{a}, *$, Ouyang Zhi-yun ${ }^{a}$, Zhu Chun-quan ${ }^{b}$ \\ a State Key Laboratory of Urban and Regional Ecology, Research Center for Eco-Environmental Sciences, Chinese Academy of Sciences, Beijing 100085, China \\ ${ }^{\mathrm{b}}$ WWF-China, Beijing 100006, China
}

\section{A R T I C L E I N F O}

\section{Article history:}

Received 24 June 2013

Received in revised form

10 December 2013

Accepted 27 February 2014

\section{Keywords:}

Biodiversity

Human impact

MARXAN

Priority area

Systematic conservation planning

\begin{abstract}
A B S T R A C T
Because of limitation of manpower, funding, and land available in conservation, the problem of how to select essential regions to establish protection systems for biodiversity maintenance has been widely discussed. In an effort to address the problem, this study has aimed to select a set of priority areas and to determine their priority order by quantifying human disturbances for each area in the Yangtze River Basin (YRB). This basin covers 2.143 million $\mathrm{km}^{2}$, or more than $20 \%$ of China's territory. The habitats of 627 indicator species were predicted as a proxy for biodiversity. A conservation planning tool, MARXAN, was used to determine the optimal set of planning units, and three different target scenarios were generated. In addition, under the assumption that if two areas have equal value for conservation, the one suffering more severe disturbance needs more urgent protection than the other, priority ranking analysis was carried out using a 6-12-1 BP artificial neural network. Then hierarchical cluster analysis was applied to the classifications of human disturbances to formulate more detailed conservation strategies. By integrating the degree of irreplaceability of each unit, expert experience, and mountain boundaries, 17 biodiversity priority areas containing 33,200 units over an area of 0.83 million $\mathrm{km}^{2}$ were defined. These areas also protected $56 \%$ of 32 types of rare forest ecosystem and $76.4 \%$ of six types of rare grassland ecosystem on average. According to the evaluation of human impact, a priority order and five types of human disturbance areas were generated. Some protection gaps were also identified, such as the northern part of the Wuyi Mountains. Moreover, the determination of priority nature conservation areas on a large scale can be used to influence the building of a well-connected protection network in each individual area, so that effective genetic communication can occur between species or groups of species. Conservation decisions focusing on the dominant impact factors that are threatening biodiversity sustainability are required as well.
\end{abstract}

(c) 2014 Elsevier GmbH. All rights reserved.

\section{Introduction}

Biodiversity provides many products and services for humanity; however, in recent years, many species have become increasingly threatened by anthropogenic disturbances (Cardinale et al., 2012). To ensure long-term biodiversity maintenance, conservation actions must be urgently undertaken. These actions involve both in situ and ex situ conservation (Sarkar et al., 2002). In comparison with ex situ conservation, in situ conservation is more concerned with conservation in the conventional sense because it concentrates more on the preservation of intrinsic features and the long-term sustainability of biodiversity. A well-balanced in situ conservation

\footnotetext{
* Corresponding author.

E-mail address: xuweihua@rcees.ac.cn (W.-h. Xu).
}

system will protect biodiversity from the stresses of human activities (Bruinderink et al., 2003; Wu et al., 2011). Nevertheless, in the real world, funding limitations on land conservation initiatives lead to conflicts between economic development and conservation. This issue forces decision-makers to identify essential regions with low economic potential for conservation investment (Pressey et al., 2007).

Methods for selecting priority conservation areas generally include four aspects: mapping biodiversity richness using remote sensor data (Ranjeet et al., 2008; Rocchini et al., 2010); spatial clustering to identify planning units (Dunstan et al., 2012; Yu et al., 2005); eco-regional identification according to the distribution of rare ecosystems and ecosystem services (Egoh et al., 2007; Rogers et al., 2010); and site-selection algorithms (Lehtomäki \& Moilanen, 2013; Possingham et al., 2000). Among these, site-selection algorithms have the unique advantage of being able to determine the mathematically optimal reserve system (Vanderkam et al., 2007). 
Using optimality as the core concept, systematic conservation planning combines many of the principles of conservation planning (e.g., total area, connectivity, spatial patterns, socioeconomic costs) to make explicit, effective, and accountable decisions that result in the reasonable allocation of scarce conservation resources (Margules \& Pressey, 2000). Because of its advantage in the tradeoff between economic development and nature conservation, this approach is highly compatible with developing areas which are under increasing stress from human populations and land-use dynamics.

The Yangtze River Basin (YRB), the largest drainage basin in China, has experienced a booming economy over the last decade, and therefore human disturbances that negatively affect natural biodiversity have intensified. The YRB, as a globally crucial region for biodiversity conservation, contains a huge number of rare and indigenous species. More than 14,000 higher plants, 280 mammals, 762 birds, 145 amphibians, and 166 reptiles are represented in the YRB (Ouyang \& Zhu, 2011). Meanwhile, settlements, roads, mineral-resource extraction, tourism, and many other types of human activity are widely and densely distributed across the basin, causing serious disturbances and threatening biodiversity within the region. Apparently, this has led to conflicts when selecting priority areas that are suitable for conservation status. In an attempt to address this problem in part, Heiner et al. (2011) identified a set of conservation areas for the protection of adequate biodiversity in the upper YRB based on the idea of systematic conservation planning, which represented important progress in conservation planning in this region. By contrast, this research presents the results of explicit conservation plans for the whole basin that focus mainly on terrestrial biodiversity and evaluate human disturbance independently to gather information that can be used to manage and improve conservation in this area, instead of being a component in the algorithm as a proxy of conservation cost.

The cost calculations associated with conservation are an important part of any systematic conservation plan. Cost estimation is a very positive and constructive contribution to the cost-benefit tradeoffs that occur during conservation planning. However, in many cases, it is difficult to quantify the economic costs of conservation, not only in monetary terms, but also according to other metrics (Banks \& Skilleter, 2007). Therefore, a composite human-disturbance index has been developed by combining various factors, assuming that a planning unit with serious human impact incurs higher costs (Wilson et al., 2005). However, some regions with high conservation value are constantly managing the pressure of dealing with human needs, which forces them to be even more protective of their natural resources. Unless an alternative low-impact habitat is available, these areas are often developed because of their high associated economic potential. To avoid abandoning these high-value areas, threatening human factors should be considered separately rather than as a cost proxy. Some areas with intrinsic vulnerabilities demonstrate various levels of human impact where severe conflict exists between conservation initiatives and human activities. Once biodiversity has been destroyed, however, it is difficult to restore it to these regions due to their fragile nature and unique characteristics (Safont et al., 2012). In addition, analysis of human interference using site-selection algorithms enables decision-makers to make reasonable adjustments for resources, which makes a strong contribution to meeting conservation targets in priority areas. For this purpose, an ANN model was constructed to rank areas in terms of conservation priority, rather than merely by order of habitat irreplaceability. For example, if a unit has both high cost and high conservation values, an optimization procedure tends to abandon it due to fiscal concerns. However, these units require urgent investments that are separate from human pressures and have never been ignored. This is why human impact analysis was not included in the algorithm.
In this study, the first step was to identify indicator species and simulate their habitats to compile a dataset as a surrogate for biodiversity. The criteria for indicator species included the protection level and degree of endemic status according to several Red Lists. Maps of the predicted habitats were determined using several environmental variables that affect species habitat (e.g., altitude, vegetation type, slope, and aspect), which were obtained from the datasets of various historical research reports and field samples. Each variable was converted to a Boolean image that constrained the habitat to specific geographic regions. All these modeling results are required to use MARXAN (Marine Reserve Design using Spatially Explicit Annealing) (Game \& Grantham, 2008), a site-selection algorithm developed to identify areas with high conservation value. Here, MARXAN was used to aid in the selection of suitable conservation sites in the YRB. After the sites were determined, human disturbance was estimated using an ANN model to quantify the characteristics and the degree of human impacts in each priority nature-conservation area.

The objectives of this research, therefore, were to obtain a solution for optimal-priority areas in the YRB and to analyze several target scenarios to obtain alternative conservation plans. In addition, quantitative analysis of the human impact in each priority area was performed by integrated estimation that considered several categories of existing threat factors, with the expectation that more specific conservation measures would be generated for priority areas.

\section{Methods}

\section{Study area}

The YRB and its neighboring regions include 829 counties, cities, and districts in 19 provinces. The total area of this watershed is approximately 1.8 million $\mathrm{km}^{2}$, or $18.8 \%$ of China's territory. The river can be divided into three sections: (1) from the headwaters to Yichang, also known as the upper reaches $(4504 \mathrm{~km}$; 1 million $\mathrm{km}^{2}$ drainage area); (2) Yichang to Hukou, or the middle reaches ( $955 \mathrm{~km}$; 0.68 million $\mathrm{km}^{2}$ drainage area); and (3) Hukou to the estuary, or the lower reaches $\left(938 \mathrm{~km} ; 0.12\right.$ million $\mathrm{km}^{2}$ drainage area). After considering the integrity of the ecosystem and wildlife habitat, the research area was extended to include the Qiangtang Plateau, the Ruo'ergai marshes, the northern slope of the Qinling Mountains, Hunan Province, Jiangxi Province, and the Qiantang River basin in Zhejiang Province. The combined study area is 2.143 million $\mathrm{km}^{2}$ in total (Fig. 1).

\section{Indicator species}

Species were required to meet at least one of the following selection criteria to be considered as indicators of biodiversity: (1) indigenous to China and endangered; (2) found mainly in China and endangered; (3) indigenous to China and under threat according to the IUCN Red List of Threatened Species (IUCN, 2004) and First Volume of the Red Data List of Chinese Species (Wang \& Xie, 2004).

Species distributions were modeled using data included in species-location datasets or existing field studies, including (1) China Animal Scientific Database (CAS, 2011a); (2) Scientific Database of China Plant Species (CAS, 2011 b); (3) Chinese Biodiversity Information System (CAS, 2005); and (4) Chinese Species Information System (CAS, 2001). The major types of vegetation, altitude, species, and other habitat data (e.g., aspect, slope) were determined from these databases and used in biodiversity richness mapping using the spatial analysis function of geographic information system (GIS) tools. All maps are presented in Boolean format. 


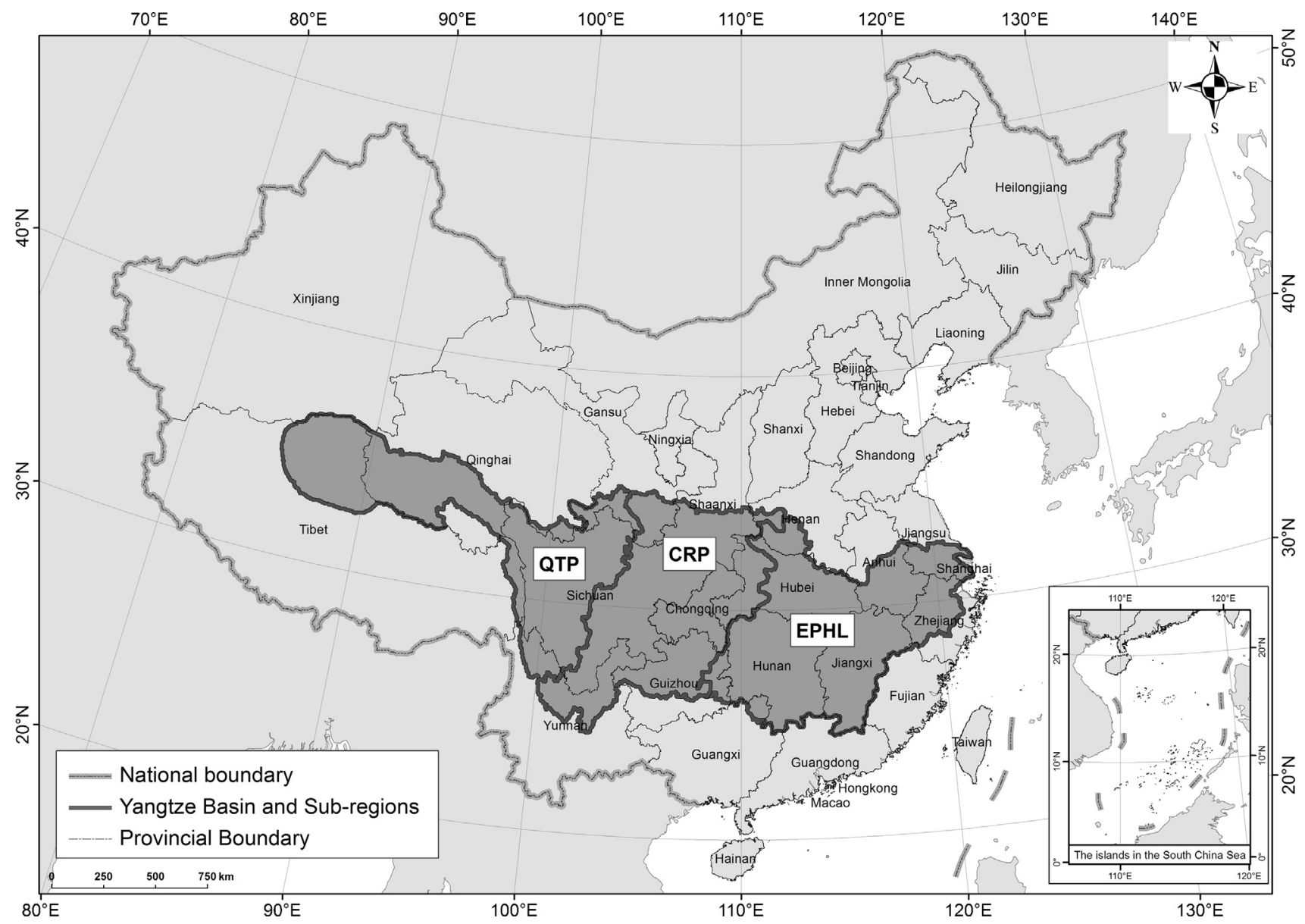

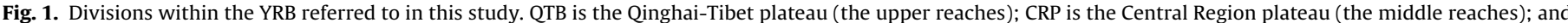
EPHL is the eastern plain and hilly lands (the lower reaches).

\section{Site-selection algorithm}

The identification of priority conservation areas was performed using MARXAN (v. 1.8.10) (Game \& Grantham, 2008), which is a software program that provides decision support for designing reserve systems within a GIS interface. MARXAN enables the conservation planner to select new conservation areas from a large number of potential sites (or planning units). The degree of irreplaceability of each planning unit was used to facilitate the selection algorithm (Ferrier et al., 2000). This means that areas with higher irreplaceability also have a higher conservation value. A spatially explicit solution that was correlated with the indicator species was also calculated and mapped.

MARXAN requires explicit targets for biodiversity features. An explicit target for habitat proportion defines the extent of species habitat that is sufficient to achieve an acceptable risk level of extinction. However, only a few methods are recognized to translate existing datasets and undocumented data into quantitative targets for indicator species (Justus et al., 2008). To obtain alternative decisions, three target scenarios were simulated. These target scenarios were: (a) to protect $60 \%$ of overall habitat for all indicator species; (b) to protect $30 \%$ of overall habitat area for all indicator species; and (c) to assign different protection targets $(60 \%, 40 \%$, or $30 \%)$ to species with different levels of rarity according to the three grades specified above.

The basin was then divided into 85,694 square planning units ( $25 \mathrm{~km}^{2}$ per unit). Although using sub-catchments as planning units may describe ecological processes better than the more commonly used square or hexagonal planning units (Klein et al., 2009), it is difficult to map accurately all sub-catchments in a 2.143 million $\mathrm{km}^{2}$ region, especially in areas with complex geomorphological and hydrological characteristics. Therefore, square planning units were used. In addition, the YRB runs along three terrain gradients in China that have different climates, ecosystems, and species compositions. For example, there are huge numbers of indicator species in every geographic region (e.g., the Hengduan and Qinling Mountain regions). Some parts of rare habitat for a single indicator species may be neglected by the algorithm because they require higher concentrations in areas with high species richness. This part of a habitat might have several important biological functions, such as acting as a migration corridor or being the habitat of a crucial subpopulation. To ensure that areas with relatively high conservation values were distributed across the whole basin (rather than aggregated into a few large regions), the YRB was further divided into three zones according to average latitude: the Qinghai-Tibet plateau (QTP), the Central Region plateau (CRP), and the eastern plains and hilly lands (EPHL) (Fig. 1). Each zone had its own internal site-selection algorithm. The same cost was applied to all planning units because the overall aim was first to determine the minimum number of planning units needed for the conservation network and to define targets, and then to estimate the level of human disturbance.

Running MARXAN requires a series of parameters, of which some can be given default values and others must be repeatedly checked and debugged using quantifiers such as the Boundary Length Modifier (BLM) or the Species Penalty Factor (SPF). The SPF was set to 500 to ensure that every species would meet its target (Geselbracht et al., 2009). The BLM is a parameter that helps control 
Table 1

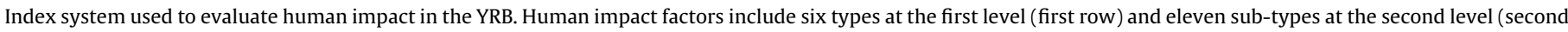
row).

\begin{tabular}{|c|c|c|c|c|c|}
\hline Settlements & $\begin{array}{l}\text { Transportation } \\
\text { infrastructure }\end{array}$ & Mines & $\begin{array}{l}\text { Hydro-electric } \\
\text { station }\end{array}$ & Tourism & Farmland \\
\hline Urban and rural residents & $\begin{array}{l}\text { National, provincial, } \\
\text { and county roads }\end{array}$ & $\begin{array}{l}\text { All kinds of } \\
\text { mines site }\end{array}$ & & $\begin{array}{l}\text { Forest parks, } \\
\text { geo-parks, culture and } \\
\text { natural heritage sites }\end{array}$ & $\begin{array}{l}\text { Rice paddies, } \\
\text { land dry land }\end{array}$ \\
\hline
\end{tabular}

Table 2

Characteristics of indicator species and protection levels in YRB and its sub-regions.

\begin{tabular}{|c|c|c|c|c|c|c|c|}
\hline Region & Level & Amphibian & Avian & Reptile & Mammal & Plant & Total \\
\hline \multirow{3}{*}{ YRB } & I & 7 & 2 & 5 & 12 & 133 & 159 \\
\hline & II & 1 & 7 & 4 & 25 & 49 & 86 \\
\hline & III & 24 & 28 & 12 & 34 & 284 & 382 \\
\hline \multirow{3}{*}{ QTP } & I & 3 & 0 & 0 & 10 & 49 & 62 \\
\hline & II & 0 & 2 & 1 & 18 & 18 & 39 \\
\hline & III & 9 & 20 & 4 & 28 & 188 & 249 \\
\hline \multirow{3}{*}{ CRP } & I & 6 & 2 & 2 & 8 & 93 & 111 \\
\hline & II & 1 & 2 & 3 & 17 & 29 & 52 \\
\hline & III & 22 & 18 & 8 & 27 & 188 & 263 \\
\hline \multirow{3}{*}{ EPHL } & I & 2 & 0 & 4 & 2 & 33 & 41 \\
\hline & II & 1 & 4 & 2 & 11 & 23 & 41 \\
\hline & III & 4 & 6 & 5 & 11 & 90 & 116 \\
\hline
\end{tabular}

for spatial compactness in priority areas. By increasing the BLM, the number of planning units was increased to connect isolated units with high conservation values. Therefore, some units with low biodiversity richness could be selected, which would enlarge the total area as a result. To obtain results with moderate clustering, an index (Eq. (1.1)) was used to calculate the effectiveness of the BLM:

$\mathrm{SI}=\frac{0.25 L}{\sqrt{A}}$,

where $L$ is the total boundary length and $A$ is the total area. The BLM value at the point of moderate compaction was regarded as the best value from among the different results along the SI curve.

To demonstrate the effectiveness of rare ecosystem conservation using the areas identified, the status of each type of rare ecosystem was analyzed according to the defined priority scheme.

\section{Assessment and classification of human disturbance}

According to the selected priority areas, the level of human disturbance in each area was calculated as an indicator for priority sequencing. This would mean that conservation funds and resources could be reallocated to regions with higher levels of human disturbance. Twelve variables covering six aspects of disturbance (settlement, transportation infrastructure, mines, hydroelectric stations, tourism, and farmland) were selected to assess human disturbance in the priority areas (Table 1). All data were vectorized to GIS format.

The 6-12-1 BP artificial neural network was used to estimate human disturbance. In the authors' experience, other methods of analysis cannot universally weigh and assess all indicators in a distinct ecosystem. All variables were normalized to between 0 and 1 using a normalization function (Eq. (1.2)) to avoid convergent results:

$x_{i}^{*}=\frac{x_{i}}{\max x_{i}}$,

where $x_{i}^{*}$ is the normalized value of variable $i, x_{i}$ is the original value of variable $i$, and $\max x_{i}$ is the maximum value of this variable in
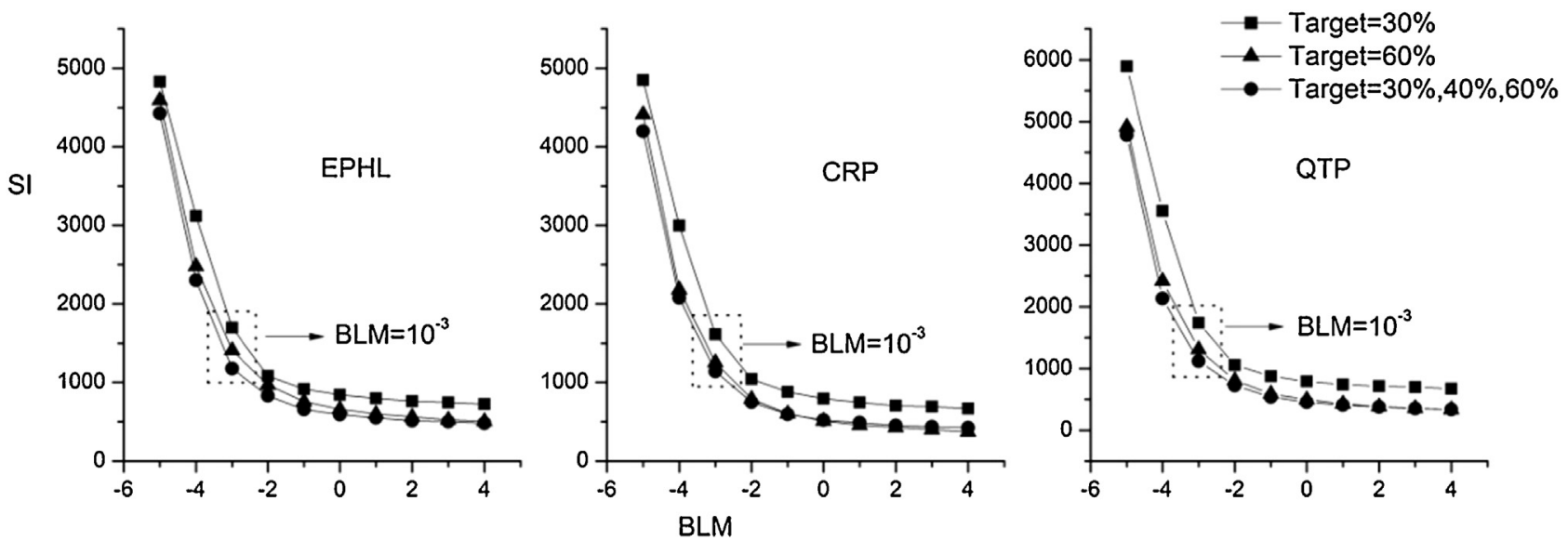

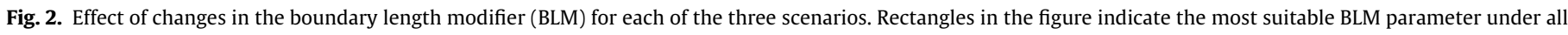
scenarios. SI indicates the degree of spatial compaction of the algorithm results. 


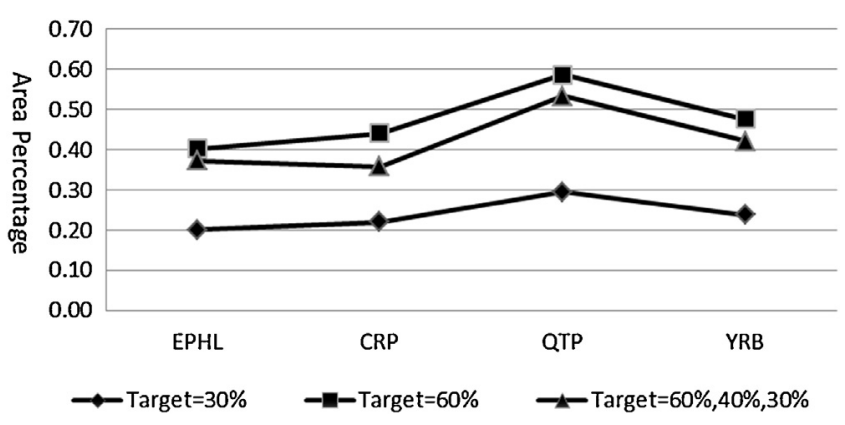

Fig. 3. Relationship between conservation areas (expressed as a percentage of protected land) and targets for each of the three scenarios for the YRB as a whole and for each of the three YRB subareas (EPHL, CRP, and QTP).

all priority areas. The logsig activation function (Eq. (1.3)) was used because all values were $>1$ :

$f(x)=\frac{1}{1+e^{-x}}, \quad 0 \leq f(x) \leq 1$

The learning rate, momentum constant, and convergence error were $0.01,0.7$, and $0.5 \times 10^{-5}$ respectively. Hierarchical cluster analysis was then used to classify priority areas according to the main types of human impact.

\section{Results}

Characteristics of the indicator species

Using the criteria described earlier for defining indicator species, 627 indicator species were identified, including 32 amphibians, 466 higher plants, 71 mammals, 32 birds, and 21 reptiles (Table 2).Zonal statistics show that 350,426 , and 198 indicator species were found in QTP, CRP, and EPHL respectively. The QTP and the CRP apparently contain more rare species than the EPHL. However, the EPHL provides habitats for many globally rare and endangered species, such as the Chinese alligator (Alligator sinensis) and Cabot's tragopan (Tragopan caboti) that cannot be ignored.

\section{BLM and comparisons of different target scenarios}

For each zone and scenario, 10 algorithms were executed under various BLM values between $10^{-5}$ and $10^{4}$ to identify the most suitable point. As the SI curves show (Fig. 2), areas of moderate compaction were most likely to appear at $10^{-3}$. Although the total area was still increasing, the rate of decrease in boundary length was the most severe at this point.

The algorithm generated two kinds of solutions: the single best solution, and the best solution in terms of irreplaceability. For each of the three zones, the single best solution for each scenario completely met the conservation target. Meanwhile, nine priority area
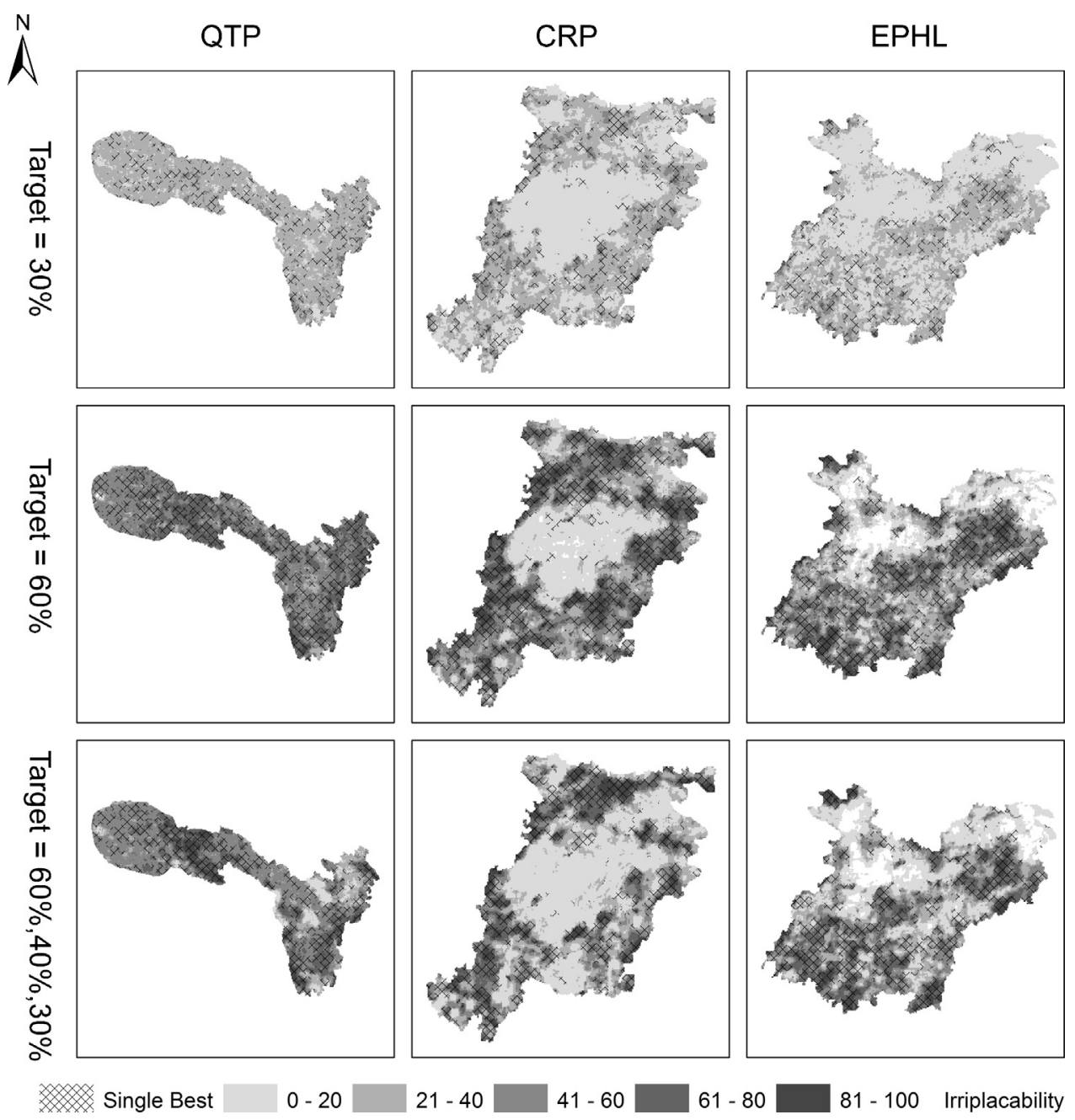

Fig. 4. Spatial distribution of the three districts under three different scenarios according to the site-selection algorithm. 
Table 3

Region names, geographic areas, and major ecosystem types of the 17 selected priority areas.

\begin{tabular}{|c|c|c|c|}
\hline Region & Geographic area & Major types of ecosystem & Area $\left(\mathrm{km}^{2}\right)$ \\
\hline South Qinghai & Sub-frigid zone, humid plateau regions & Alpine steppe, mountainous steppe & 100,677 \\
\hline Yangtze source & Sub-frigid zone, humid plateau regions & Alpine steppe, mountainous steppe & 200,020 \\
\hline Minshan & Temperate plateau zone & Mountainous coniferous forest, alpine meadow & 35,685 \\
\hline Qionglai & Temperate plateau zone & Mountainous coniferous forest, alpine meadow & 27,825 \\
\hline Liangshan-Xiangling & Mid-subtropical zone & Mountainous evergreen, broadleaf forest & 36,293 \\
\hline Shennongjia & Northern subtropical zone & Mixed mountainous needle and broadleaf forest & 26,577 \\
\hline Wuling mountains & Mid-subtropical zone & Plateau evergreen and broadleaf forest & 30,084 \\
\hline Upper Jinsha River & Temperate plateau zone & Mountainous coniferous forest, alpine meadow & 68,203 \\
\hline Hengduan mountains & Mid-subtropical zone & Mountainous evergreen broadleaf forest & 76,389 \\
\hline Dalou mountains & Mid-subtropical zone & Plateau evergreen and broadleaf forest & 24,589 \\
\hline Wannan mountains & Northern subtropical zone & Mixed mountainous needle and broadleaf forest & 14,244 \\
\hline Luoxiao mountains & Mid-subtropical zone & Mixed mountainous needle and broadleaf forest & 47,562 \\
\hline Daduhe source & Temperate plateau zone & Mountainous coniferous forest, alpine meadow & 19,045 \\
\hline Qinling & Northern subtropical zone & Mixed mountainous needle and broadleaf forest & 45,785 \\
\hline Northern part of the Wuyi mountains & Mid-subtropical zone & Mountainous evergreen and broadleaf forest & 10,807 \\
\hline Nanling mountains & Mid-subtropical zone & Mixed mountainous needle and broadleaf forest & 56,111 \\
\hline Dabie mountains & Northern subtropical zone & Mixed mountainous needle and broadleaf forest & 10,106 \\
\hline
\end{tabular}

sets were obtained for different scenarios with different targets. The relationship between targets and areas is shown in Fig. 3 .

The scenario which aimed to protect only $30 \%$ of the habitat needed by all indicator species had significantly smaller conservation areas than the other two target scenarios, which both included all the areas in the first scenario. Moreover, this scenario neglected a large area with high biodiversity richness due to its low target value, and therefore it was not helpful in selecting priority areas. As for the second scenario (60\% of total land protected; Fig. 4), which occupies a vast area of the YRB and QTB, it was equally difficult to determine an adequate solution.

By contrast, the third scenario, which assigned different protection targets to species with different levels of rarity, obtained the most reasonable results. This was not only because of its moderate area requirements, but also because of the different conservation values assigned to the different indicator species.

\section{Spatial patterns of the biodiversity conservation system}

By integrating the solutions of the third scenario and applying expert experience, a set of priority areas were selected that best represent places where biodiversity should be maintained. Using this procedure, the degree of irreplaceability was used to determine the locations and boundaries of the priority areas. In addition, irreplaceability is important when deciding how to expand existing protected areas (Nel et al., 2009).

After examining the data on irreplaceability and biodiversity, 17 priority areas were selected (Table 3) according to several principles. First, planning units with high irreplaceability were characterized as the major habitats of first-level indicator species that demonstrate very limited distribution ranges within the YRB. Second, important regions that maintain biodiversity richness or special biodiversity processes, such as reproduction or migration, were selected. Third, areas that typically support species in vulnerable ecosystems were selected. Finally, areas with high irreplaceability, but low conservation value were removed.

\section{Conservation of rare ecosystems}

Thirty-seven rare forest ecosystems and six grassland types (Table 4) are distributed in the YRB (Li et al., 2003). Intersection analysis indicates that the 17 priority areas enclose $48.4 \%$ of the rare forest ecosystems and $76.4 \%$ of the rare grassland ecosystems on average. Except for five forest types which do not appear in all the areas, the average percentage of protected rare forest ecosystems can be as high as $56 \%$, which is close
Table 4

Percentages of the area of rare ecosystems within the priority conservation areas identified. The last six types are grassland ecosystems.

\begin{tabular}{|c|c|}
\hline Name of rare ecosystem & $\begin{array}{l}\text { Proportion within } \\
\text { the priority areas }\end{array}$ \\
\hline Abies forestii C. C. Rogers & $68.6 \%$ \\
\hline Picea likiangensis (Franch) Prtiz & $77.2 \%$ \\
\hline Abies Faxoniana Rehd. et Wils & $54.2 \%$ \\
\hline Picea asperata Mast & $33.5 \%$ \\
\hline $\begin{array}{l}\text { Picea likiangensis var. Balffouriana (Rehd. Et } \\
\text { Wils.) Hiller ex Slavin }\end{array}$ & $55.7 \%$ \\
\hline Picea purpurea Mast & $51.6 \%$ \\
\hline $\begin{array}{l}\text { Picea brachytyla var. Complanata (Mast) Cheng } \\
\text { ex Rehd }\end{array}$ & $59.8 \%$ \\
\hline Larix potaninii Batal & $32.1 \%$ \\
\hline Sabina tibetica Kom & $60.3 \%$ \\
\hline Sabina saltuaria (Rehd. Et Wils) & $70.2 \%$ \\
\hline Sabina przewalskii Kom & 0 \\
\hline Pinus babulaeformis Carr & $46.3 \%$ \\
\hline Pinus bungeana Zucc & $48.3 \%$ \\
\hline Pinus armandii Franch & $57.0 \%$ \\
\hline Pinus armandii Franch & $69.2 \%$ \\
\hline Pinus taiwanensis & $80.1 \%$ \\
\hline Pinus henryi Mast & $39.6 \%$ \\
\hline Platycladus Spach & $53.8 \%$ \\
\hline Cryptomeria fortunei Hooibrenk & 0 \\
\hline Pinus yunnanensis & $50.1 \%$ \\
\hline Pinus yunnanensis var. Tenuifolia Cheng et La & $93.8 \%$ \\
\hline $\begin{array}{l}\text { Pinus yunnanensis var. Langbianensis (A. Chev.) } \\
\quad \text { Gaussen }\end{array}$ & 0 \\
\hline Keteleeria evelyniana Mast & 0 \\
\hline Cathaya argyrophylla & $40.7 \%$ \\
\hline Cupressus $L$ & $6.5 \%$ \\
\hline Quercus liaotungensis Koiz & $42.1 \%$ \\
\hline $\begin{array}{l}\text { Quercus variabilis Bl. -Quercus serrata var. } \\
\text { Brevipetiolata (DC.) Hakia-Castanopsis } \\
\text { sclerophylla (Lindl.) Schoot. -Cyclybalanopsis } \\
\text { glauca (Thunb.) Oerst }\end{array}$ & $49.0 \%$ \\
\hline Quercus acutissima & $40.1 \%$ \\
\hline Cyclobalanopsis & $76.1 \%$ \\
\hline Fagus longipetiolata Seem. -gravel oak & $95.9 \%$ \\
\hline Castanopsis sclerophylla (Lindl.) & $36.7 \%$ \\
\hline Castanopsis delavayi & $0.6 \%$ \\
\hline Castanopsis fargesii & $44.5 \%$ \\
\hline Castanopsis fargesii Franch & $65.0 \%$ \\
\hline Castanopsis fabri & $58.0 \%$ \\
\hline Quercus aquifoliodes Rehd.et Wils & $66.5 \%$ \\
\hline Quercus cocciferoides Hand. Mazz & $68.2 \%$ \\
\hline Tibetan bellard kobresia meadow & $76.7 \%$ \\
\hline $\begin{array}{l}\text { Weed meadow dominated by gardan burnet and } \\
\text { ivyleaf bellard kobresia }\end{array}$ & $100.0 \%$ \\
\hline Stipa purpurea & $94.8 \%$ \\
\hline Small bellard kobresia meadow & $60.9 \%$ \\
\hline Yunnan gueldenstaedtia & $91.4 \%$ \\
\hline Sheep fescue & $34.7 \%$ \\
\hline
\end{tabular}


Table 5

Criteria used for assessing human impact in this study (ps means points with *.shp format).

\begin{tabular}{|c|c|c|c|c|c|c|}
\hline Impact & $\begin{array}{l}\text { Hydroelectric plants } \\
\left(\mathrm{ps} / 100 \mathrm{~km}^{2}\right)\end{array}$ & $\begin{array}{l}\text { Mines } \\
\left(\mathrm{ps} / 100 \mathrm{~km}^{2}\right)\end{array}$ & $\begin{array}{l}\text { Transportation } \\
\left(\mathrm{km} / 100 \mathrm{~km}^{2}\right)\end{array}$ & $\begin{array}{l}\text { Settlements } \\
\left(\mathrm{ps} / 100 \mathrm{~km}^{2}\right)\end{array}$ & $\begin{array}{l}\text { Tourism } \\
\left(\mathrm{ps} / 100 \mathrm{~km}^{2}\right)\end{array}$ & $\begin{array}{l}\text { Farmland } \\
\left(\mathrm{km}^{2} / 100 \mathrm{~km}^{2}\right)\end{array}$ \\
\hline \multirow[t]{2}{*}{ Slight } & 0 & 0.0137 & 0.6762 & 0.1069 & 0 & 0 \\
\hline & 0 & 0.1409 & 3.4509 & 2.5935 & 0.0009 & 0.7469 \\
\hline \multirow[t]{4}{*}{ Moderate } & 0 & 0.2599 & 5.3752 & 5.2458 & 0.0081 & 4.3659 \\
\hline & 0.0043 & 0.2759 & 6.8067 & 8.2805 & 0.0183 & 11.1690 \\
\hline & 0.0053 & 0.4026 & 9.1631 & 11.6472 & 0.0250 & 13.6603 \\
\hline & 0.0091 & 0.5724 & 11.8252 & 12.7371 & 0.0280 & 15.1490 \\
\hline \multirow[t]{2}{*}{ Heavy } & 0.0141 & 0.6772 & 12.8543 & 14.1302 & 0.0320 & 15.6967 \\
\hline & 0.0249 & 0.8263 & 16.2005 & 14.8656 & 0.0412 & 19.4874 \\
\hline \multirow[t]{2}{*}{ Severe } & 0.0351 & 1.4980 & 17.9077 & 16.0145 & 0.0601 & 26.8119 \\
\hline & 0.0431 & 2.2948 & 20.5578 & 16.4342 & 0.0632 & 35.4581 \\
\hline
\end{tabular}

to the conservation target for first-level indicator species. These five absent types of ecosystem represent two situations. Some of them are verge habitats with only a small area in the YRB and their main extent in other parts of China, such as Sabina przewalskii Kom, Cryptomeria fortunei Hooibrenk, Pinus yunnanensis var. Langbianensis (A. Chev.) Gaussen, and Keteleeria evelyniana Mast. Others consist of Castanopsis delavayi, which has been well protected $(62.7 \%$ of total area) by existing conservation networks.

\section{Level of human disturbance in each area}

BP artificial neural networks (BP-ANN) can be used to assess complex projects using multiple variables that depict the target system. Table 5 provides a set of evaluation criteria in which every joint at $10 \%$ intervals of each maximum factor value were used as training data.

The BP-ANN generated an assessment of levels of human impact for all the selected priority areas, as shown in Fig. 5. Three priority areas included areas with severe human disturbance, including the northern part of the Wuyi Mountains (0.9932), and nine regions included areas with heavy or moderate human disturbance. Only four of the selected priority areas had comparatively slight levels of human disturbance.

Spatially, there is a tendency to estimate lower values of human disturbance for priority areas located in the western YRB in comparison with the east. This is largely because people prefer to live in more developed areas.

Following ANN evaluation, the priority areas were further clustered into five classes according to the type of human threat, including slightly disturbed areas, areas affected by hydroelectric plants, mining areas, areas with significant human settlements, and areas characterized by extensive farmland (Fig. 6).

As shown in Fig. 7, the slightly disturbed areas are characterized by relatively few human disturbances and are all located in QTP in areas with low human population densities. Hydroelectric stations and areas with many human settlements are typically single-factor impact areas, which means that there is an obvious main threat present in these areas that is much more significant than other threats; therefore, this factor deserves special attention. Miningand farming-dominated areas demonstrate more complex impact mechanisms that not only depend on the individual impact itself, but are also seriously affected by other factors, such as transportation infrastructure and tourism, that present greater challenges to the protection of local biodiversity.

Local governments should therefore strive to relieve human pressure in highly ranked priority conservation areas and to establish specific conservation measures for all types of areas.

\section{Discussion}

Implications for improving the current conservation system

In the YRB, researchers have begun to analyze the spatial patterns of biodiversity using different approaches, such as ecosystem estimation or spatial cluster indexing (Zhang et al., 2008), ecoregional conservation methodology (Wu et al., 2006; Xu et al., 2006), and systematic conservation planning (Heiner et al., 2011; Zhang et al., 2010). These studies successfully identified areas with high conservation value under different biodiversity proxies. According to their results, until 2012, governments had established 828 nature reserves occupying over 31 present of the YRB, and numerous initiatives have been implemented over the past few decades. However, because of the relatively late start in implementing these initiatives, there are still deficiencies in connectivity and capital allocation in conservation policies, which have weakened the effectiveness of the existing reserve system. In this study, which has focused on spatial patterns of conservation priority areas with explicit conservation goals, a broader region covering $38.7 \%$ area of the entire study area was obtained. As can be seen in Fig. 8, existing nature reserves in six regions (the northern part of the Wuyi Mountains, the Dabie Mountains, the Wuling Mountains, the Wannan Mountains, the Luoxiao Mountains, and the Nanling Mountains) occupy less than 10 percent of the territory. Especially in the northern part of the Wuyi Mountains, which provides core habitat for many rare species such as Tragopan caboti and Torreyagrandis var. jiulongshanensis, there has been disturbance by complex human activities.

Based on the distribution of the conservation priority areas and their priority ranks in the YRB, these results have two implications for improving the current biodiversity system. First, according to the spatial distribution of priority areas, systematic planning of the conservation network in each individual area should be carried out, and these networks should be determined using spatially explicit boundaries that can be revised or extended to complement any existing reserve system, particularly in areas with poor conservation status. For example, using sub-catchments as the planning unit provides a better fit with both ecological processes and terrain features than using symmetrical shapes. At the same time, to reduce the extinction rate of local meta-populations further and to maintain genetic communication between species or groups of species, connectivity analyses are needed. Shelters and wild training centers for rare species should be arranged in the network according to suitable transit times to ensure that incidents involving injured or orphaned wild animals can be dealt with in good time. Second, as the ranking analysis shows, 7 out of 17 priority areas are suffering from severe human impact, but different influencing factors were identified in each case, which 


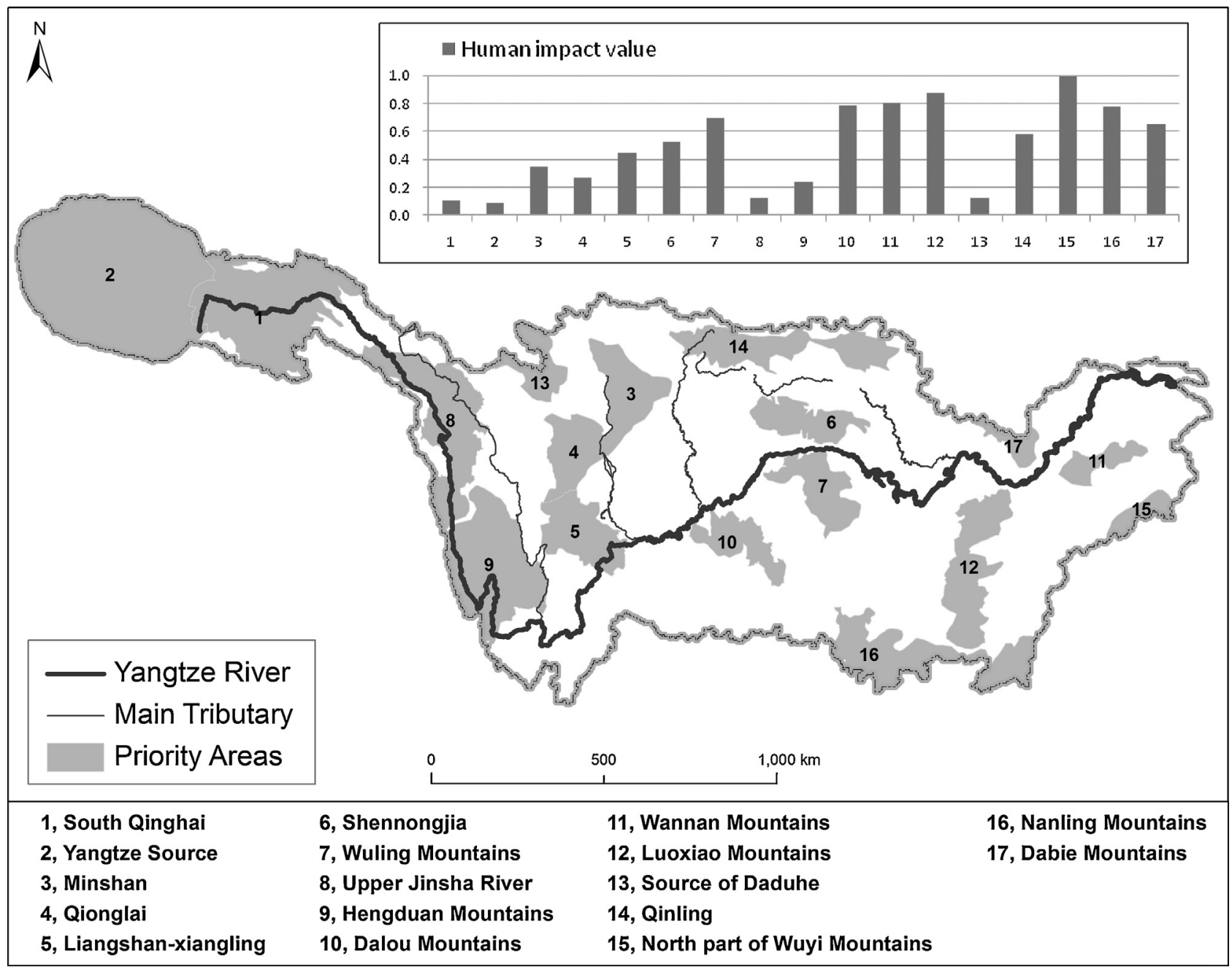

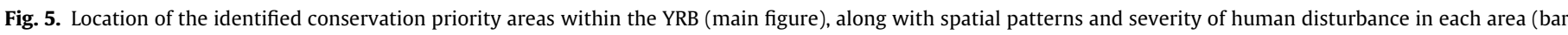
figure in the small frame).

mean that different measures need to be taken to mitigate different threats in different areas. Only one disturbance factor was readily detectable in slightly impacted areas. For example, at the Yangtze source and in South Qinghai, transportation systems play leading roles in habitat fragmentation, which has prompted management departments to set up passages for wild animals. Tougher measures are needed to protect biodiversity in more complex areas, such as reasonable attribution of nature resource royalties, restrictions on the number of tourists, and balancing ecological immigration.

\section{Limitations and further research}

This study has two important limitations. First, simulation of species habitats was limited. The most important input datum required by the algorithm is the species distribution matrix. To
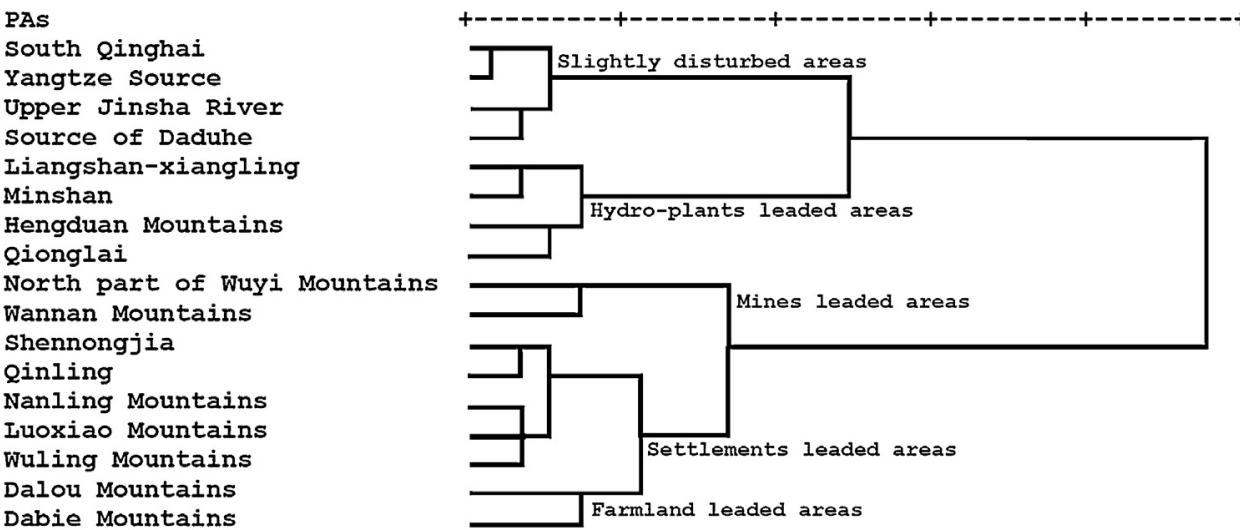

Fig. 6. Result of clustering analysis according to dominant human impact factor in conservation priority areas (PAs). 


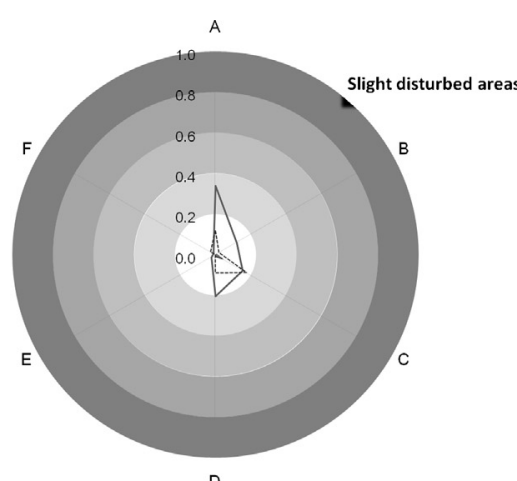

D

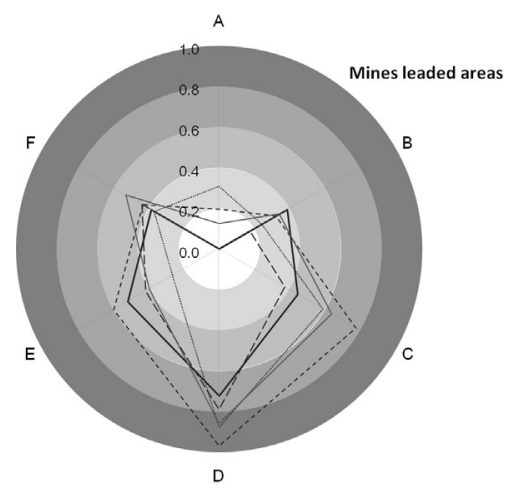

IShennongjia

Wuling Mountains

i-i Luoxiao Mountains

$\square$ Qinling

$\square$ Nanling Mountains
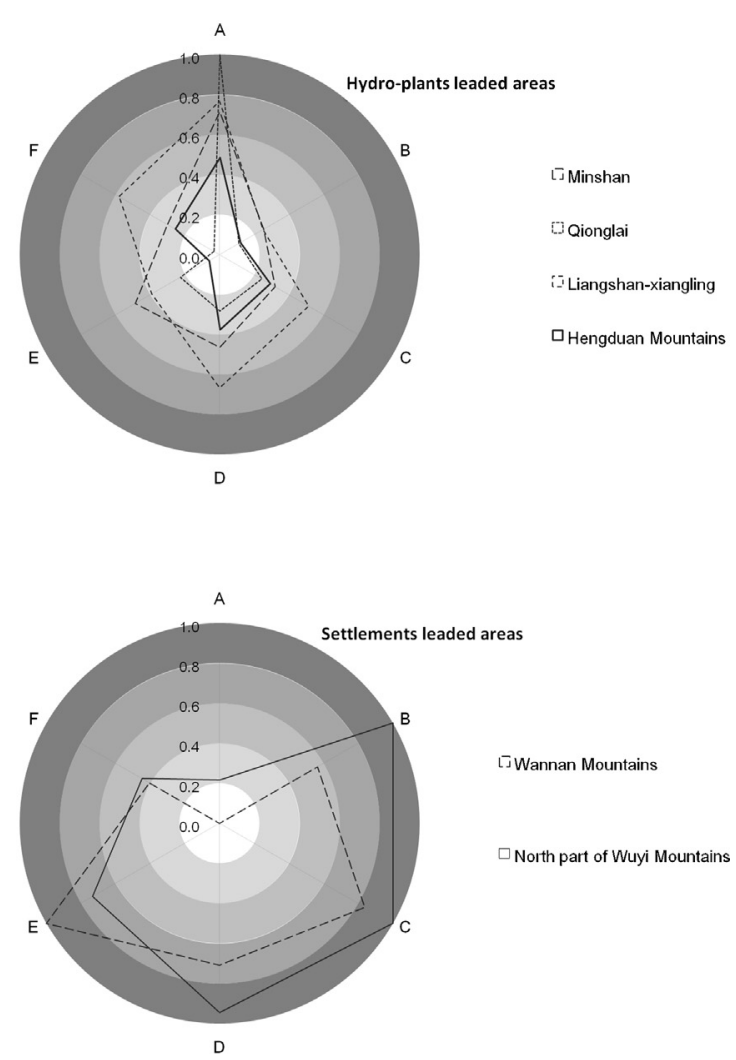

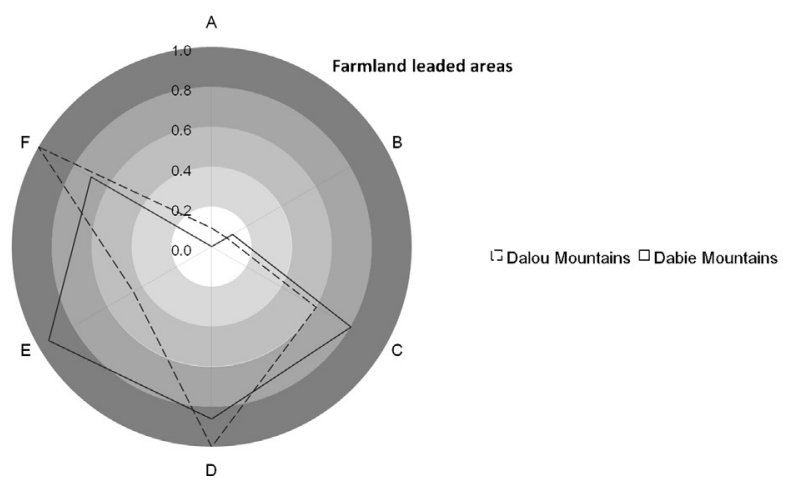

A: Hydro-plants

B: Mines

C: Transportation infrastructures

D: Settlements

E: Tourism development

F: Farmland

Fig. 7. Percentage of each specific human impact (e.g., hydroelectric plants, mining, etc.) contributing to overall human disturbance in each conservation priority area.

generate this matrix, a huge dataset of empirical data was compiled from previous studies on every indicator species over the last 30 years. During this period, as climates and landscapes changed, some species departed from their original habitats or even went extinct (Rands et al., 2010). Some ecological models, such as MAXENT and ENFA, which are based on ecological niche theory were not used in the simulations because these models require species appearance data that often come from field sampling. Most appearance data for specific species are accumulated from many different projects in different areas and seasons. Any one of these issues could lead to inaccurate habitat modeling. To maintain accuracy, each of the habitat maps was sent to experts and repeatedly modified based on feedback. The second limitation of this study is the lack of consideration of rare ecosystems as conservation targets in the algorithm. Rare ecosystems demonstrate the characteristics of the local tax on and maintain certain vital ecological processes. Actually, in deciding on the habitat for each species, "suitable ecosystems" were used as an overlap variable to ensure that rare ecosystems containing rare species could be selected into the priority areas. In addition, to demonstrate the effectiveness of the results for ecosystems protection, the percentage of rare ecosystems in the YRB was examined, and the statistical results were acceptable. However, developing a smarter method which designates both rare ecosystems and rare species in the algorithm as conservation targets would be worthwhile and should form a part of future conservation planning.

The problem of calculating conservation costs has long been discussed, but without any consensus among researchers. One well-recognized idea is that cost can be determined either monetarily or non-monetarily (Naidoo \& Iwamura, 2007). Monetary cost can be estimated using the current price of land or available opportunities, such as agricultural, forestry projects, auction cost of species, or land managers' willingness to sell (Knight et al., 2011; Naidoo \& Adamowicz, 2006; Smith et al., 2008), which act as a substitute for actual spending on conservation. Obviously, monetary cost simulation is preferred over the non-monetary method because it enables decision-makers to prepare financial reports and demonstrate 


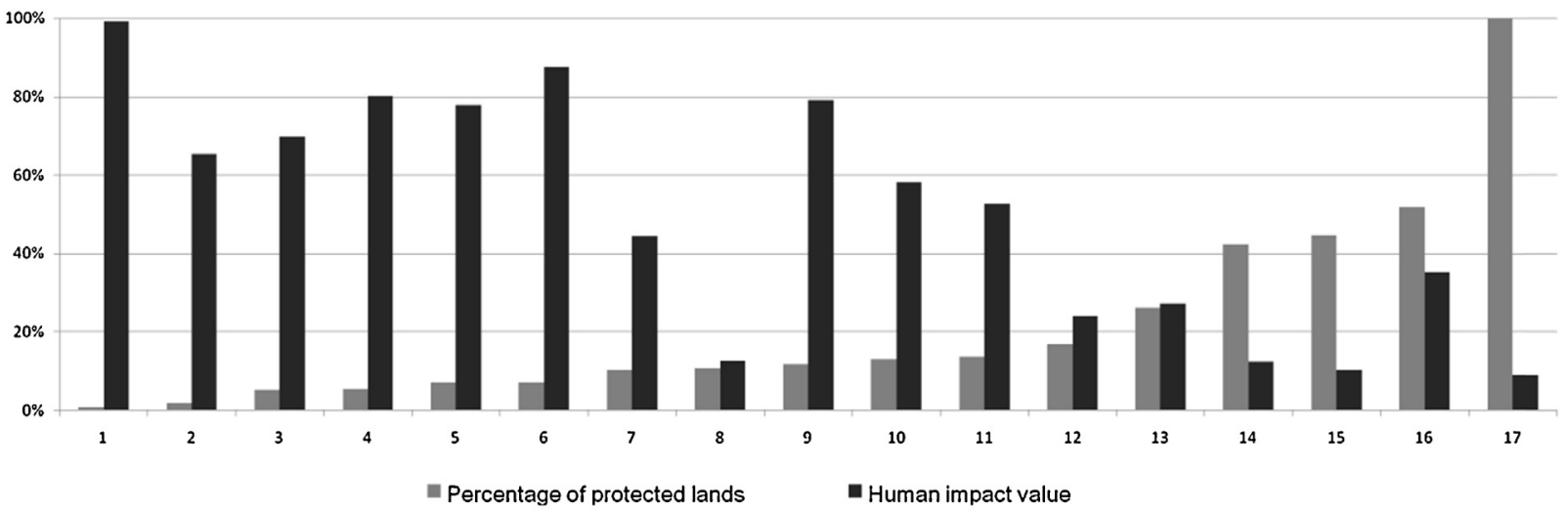

1. Northern part of Wuyi Mountains; 2. Dabie Mountains; 3. Wuling Mountains; 4. Wannan Mountains; 5. Nanling Mountains; 6. Luoxiao Mountains; 7. Liangshan-xiangling; 8. Upper Jinsha River; 9. Dalou Mountains; 10. Qinling; 11. Shennongjia; 12. Hengduan Mountains; 13. Qionglai; 14. Source of Daduhe; 15. South Qinghai; 16. Minshan; 17. Yangtze Source.

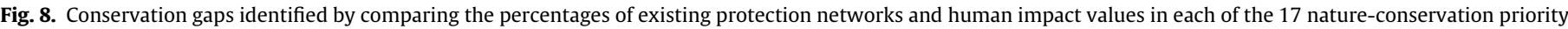
areas.

budgetary control over the reconstruction of the conservation network. Therefore, many researchers have tried to quantify the economic cost of conservation in monetary terms (Bryan et al., 2011), but there is no general model because various difficulties are encountered depending on where the model is used. For example, in China, land is nationally owned, which means that planners must focus on opportunity costs instead of acquisition costs when performing their calculations. Therefore, an important route for future studies is determining and estimating monetary cost in the YRB.

In systematic conservation planning, an explicit protection target is required by the algorithm, which is a major difference from expert-driven planning. However, setting a rational target depends greatly on the experience of experts (Cowling et al., 2003) and will unavoidably result in bias due to poor knowledge of the area and taxa. Previous studies tended to have identical goals for all biodiversity features (Ban et al., 2009) or gradated goals depending on the proximity to extinction of the species in the area (Leroux et al., 2007; Pearce et al., 2008). In this study, both methods were used to generate different results. This approach seems to be a more effective method for maximizing the conservation target level given a certain cost because it is harder to determine a fixed target than a financial expectation if an accurate cost map can be obtained. Another problem encountered when selecting targets is the specific content of the protected natural features. Pressey et al. (2003) regarded biodiversity features as individual broad habitat units, species, types of interface, discrete corridors, and gradients. This classification will be of great theoretical and practical importance in future studies. Ultimately, determining whether it is possible to use ecosystem services or vulnerability as the target in conservation planning is worthy of further study.

This paper has provided the results of priority-area mapping and large-scale evaluation of trends in these areas. Although only a relatively coarse map could be provided and some issues warrant further debate, it is crucial to develop further networks on a finer scale. The results indicate the locations, in priority rank order, that are suffering increasingly serious conflicts between human activities and biodiversity initiatives. A truly efficient conservation system that understood the relationships between ecosystems and human activities would be able to adjust for the mechanisms responsible for the environment's ecological characteristics; however, this is beyond the scope of this research. Future studies should not only include the static habitats of the included species, but should also consider species dynamics in terms of space and time.

\section{Acknowledgements}

This research was supported by the special scientific research project for public welfare industry in Ministry of Land and resources (201011018). We thank Li Zhiqi and Li Xiaoma, for their assistance in data collection.

\section{References}

Banks, S. A., \& Skilleter, G. A. (2007). The importance of incorporating fine-scale habitat data into the design of an intertidal marine reserve system. Biological Conservation, 138, 13-29.

Ban, N. C., Hansen, J. A., Jones, M. \& Vincent, A. C. J. (2009). Systematic marine conservation planning in data-poor-regions: Socioeconomic data is essential. Marine Policy, 33, 794-800.

Bruinderink, G. G., Van Der Sluis, T., Lammertsma, D., Opdam, P., \& Pouwels, R. (2003) Designing a coherent ecological network for large mammals in Northwestern Europe. Conservation Biology, 17, 549-557.

Bryan, B. A., King, D., \& Ward, J. R.(2011). Modelling and mapping agricultural opportunity costs to guide landscape planning for natural resource management. Ecological Indicators, 11, 199-208.

Cardinale, B. G., Duffy, J. E., Gonzalez, A., Hooper, D. U., Perrings, C., Venail, P., et al. (2012). Biodiversity loss and its impact on humanity. Nature, 486, 59-67.

CAS (Chinese Academy of Sciences). (2011a). China Animal Scientific Database. Available from. http://www.zoology.csdb.cn/

CAS (Chinese Academy of Sciences). (2011a). Chinese Biodiversity Information. Available from. http://cbis.brim.ac.cn/

CAS (Chinese Academy of Sciences). (2011a). Chinese Species Information System. Available from. http://csis.baohudi.org/csis_search/index.php

CAS (Chinese Academy of Sciences).(2011b). Scientific Database of China Plant Species Available from. http://db.kib.ac.cn/eflora/Default.aspx

Cowling, R. M., Pressey, R. L., Rouget, M., \& Lombard, A. T. (2003). A conservation plan for a global biodiversity hotspot-The Cape Floristic Region, South Africa. Biological Conservation, 112, 191-216.

Dunstan, P. K., Bax, N. J., Foster, S. D., Williams, A., \& Althaus, F. (2012). Identifying hotspots for biodiversity management using rank abundance distributions. Diversity and Distributions, 18, 22-32.

Egoh, B., Rouget, M., Reyers Belinda Knight, A. T., Cowling, R. M., van Jaarsveld, A. S. et al. (2007). Integrating ecosystem services into conservation assessments: A review. Ecological Economics, 63, 714-721.

Ferrier, S., Pressey, R. L., \& Barrett, T. W. (2000). A new predictor of the irreplaceability of areas for achieving conservation goal, its application to real-world planning, and a research agenda for further refinement. Biological Conservation, 93, 303-325. 
Game, E. T., \& Grantham, H. S. (2008). MARXAN user manual: For MARXAN version 1.8.10. St. Lucia, Queensland, Australia/Vancouver, British Columbia, Canada: University of Queensland/Pacific Marine Analysis and Research Association.

Geselbracht, L., Torres, R., Cumming, G. S., Dorfman, D., Michael, B., \& Shaw, D. (2009). Identification of a spatially efficient portfolio of priority conservation sites in marine and estuarine areas of Florida. Aquatic Conservation: Marine and Freshwater Ecosystems, 19, 408-420.

Heiner, M., Higgins, J., Li, X., \& Baker, B. (2011). Identifying freshwater conservation priorities in the Upper Yangtze River Basin. Freshwater Biology, 56, 89-105.

IUCN (International Union for Conservation of Nature). (2004). The IUCN Red List of threatened species. Available from. http:/www.iucnredlist.org/

Justus, J., Fuller, T., \& Sarkar, S. (2008). Influence of representation targets on the total area of conservation-area networks. Conservation Biology, 22, 673-682.

Klein, C. J., Wilson, K. A., Watts, M., Stein, J., Carwardine, J., Possingham, H. P., et al (2009). Spatial conservation prioritization inclusive of wilderness quality: A case study of Australia's biodiversity. Biological Conservation, 142, 1282-1290.

Knight, A. T., Grantham, H. S., Smith, R. J., McGregor, G. K., Possingham, H. P., \& Cowling, R. M. (2011). Land managers' willingness-to-sell defines conservation opportunity for protected area expansion. Biological Conservation, 144, 2623-2630

Lehtomäki, J., \& Moilanen, A. (2013). Methods and workflow for spatial conservation prioritization using Zonation. Environmental Modelling E' Software, 47, 128-137.

Leroux, S. J., Schmiegelow, F. K., \& Nagy, J. A. (2007). Potential Spatial Overlap of Heritage Sites and Protected Areas in a Boreal Region of Northern Canada. Conservation Biology, 21, 376-386.

Li, D., Song, Y., Ouyang, Z., Xu, W., Zhou, J., Li, Q., et al. (2003). Research on the National Forestry Nature Reserve System Plan. Beijing: China Land Press.

Margules, C. R., \& Pressey, R. L. (2000). Systematic conservation planning. Nature, $405,243-253$

Naidoo, R., \& Adamowicz, W. L. (2006). Modeling opportunity costs of conservation in transitional landscapes. Conservation Biology, 20, 490-500.

Naidoo, R., \& Iwamura, T. (2007). Global-scale mapping of economic benefits from agricultural lands: Implications for conservation priorities. Biological Conservation, 140, 40-49.

Nel, J. L., Reyers, B., Roux, D. J., \& Cowling, R. M. (2009). Expanding protected areas beyond their terrestrial comfort zone: Identifying spatial options for river conservation. Biological Conservation, 142, 1605-1616.

Ouyang, Z., \& Zhu, C. (2011). Atlas of biodiversity and conservation in the Yangtze River Basin. Beijing: Science Press.

Pearce, J. L., Kirk, D. A., Lane, C. P., Mahr, M. H., Walmsley, J., Casey, D., et al. (2008). Prioritizing avian conservation areas for the Yellowstone to Yukon Region of North America. Biological Conservation, 141, 908-924.

Possingham, H., Ball, I., \& Andelman, S. (2000). Mathematical methods for identifying representative reserve networks. New York: Springer-Verlag.

Pressey, R. L., Cabeza, M., Watts, M. E., Cowling, R. M., \& Wilson, K. A. (2007). Conservation planning in a changing world. Trends in Ecology and Evolution, 22, 583-592.

Pressey, R. L., Cowling, R. M., \& Rouget, M. (2003). Formulating conservation targets for biodiversity pattern and process in the Cape Floristic Region, South Africa. Biological Conservation, 112, 99-127.
Rands, M. R. W., Adams, W. M., Bennun, L., Butchart, S. H. M., Clements, A., Coomes, D., et al. (2010). Biodiversity conservation: Challenges beyond 2010. Science, 329, 1298-1303.

Ranjeet, J., Chen, J. Q., Lu, N., Guo, K., Liang, C. Z., Wei, Y. F., et al. (2008). Predicting plant diversity based on remote sensing products in the semi-arid region of Inner Mongolia. Remote Sensing of Environment, 112, 2018-2032.

Rocchini, D., Balkenhol, N., Gregory, A., Carter, Foody, G. M., Gillespie, T. W., et al (2010). Remotely sensed spectral heterogeneity as a proxy of species diversity: Recent advances and open challenges. Ecological Informatics, 5, 318-329.

Rogers, H. M., Glew, L., Honzák, M., \& Hudson, M. D. (2010). Prioritizing key biodiversity areas in Madagascar by including data on human pressure and ecosystem services. Landscape and Urban Planning, 96, 48-56.

Safont, E., Vilarrúbia, T. V., \& Rull, V. (2012). Use of Environmental Impact Assessmen (EIA) tools to set priorities and optimize strategies in biodiversity conservation. Biological Conservation, 149, 113-121.

Sarkar, S., Aggarwal, A., Garson, J., Margules, C. R., \& Zeidler, J. (2002). Place prioritization for biodiversity content. Journal of Biosciences, 27, 339-346.

Smith, R. J., Easton, J., Nhancale, B. A., Armstrong, A. J., Culverwell, J., Dlamini, S. D. et al. (2008). Designing a transfrontier conservation landscape for the Maputaland centre of endemism using biodiversity, economic and threat data. Biological Conservation, 141, 2127-2138.

Vanderkam, R. P. D., Wiersma, Y. F., \& King, D. J. (2007). Heuristic algorithms vs linear programs for designing efficient conservation reserve networks: Evaluation of solution optimality and processing time. Biological Conservation, 37, 349-358.

Wang, S., \& Xie, Y. (2004). First volume of the red data list of Chinese species. Beijing: Higher Education Press.

Wilson, K. A., Pressey, R. L., Newton, A. N., Burgman, M. A., Possingham, H. P., \& Weston, C. J. (2005). Measuring and incorporating vulnerability into conservation planning. Environmental Management, 35, 527-543.

Wu, B., Zhu, C., Li, D., Dong, K., Wang, X., \& Shi, P. (2006). Setting biodiversity conservation priorities in the forests of the upper Yangtze eco-region based on eco-region conservation methodology. Chinese Biodiversity, 14 87-89.

Wu, R., Zhang, S., Yu, W. D., Zhao, P., Li, X., Long, Y., et al. (2011). Effectiveness of China's nature reserves in representing ecological diversity. Frontiers in Ecology and Environment, 9, 383-389.

Xu, W., Ouyang, Z., Huang, H., Wang, X., Miao, H., \& Zheng, H. (2006). Priority analysis on conserving China s terrestrial ecosystems. Acta Ecologica Sinica, 26 271-280.

Yu, X. D., Luo, T. H., Dai, Q., Wu, Y. M., \& Zhou, H. Z. (2005). A large-scale pattern in species diversity of reptiles in the Yangtze River Basin. Chinese Biodiversity, 13 298-314.

Zhang, L., Ouyang, Z., Xu, W., Li, Z., \& Zhu, C. (2010). Biodiversity priority areas analysis for amphibians and reptiles in the Yangtze basin based on systematic conservation planning idea. Resources and Environment in the Yangtze Basin, 19 1020-1028.

Zhang, Y., Zhou, L., Wang, Q., Wang, X., \& Xing, Y. (2008). Distribution pattern and hotspot analysis of breeding birds in Anhui Province. Chinese Biodiversity, 16 305-312. 